\title{
SISTEMAS DE INFORMAÇÃO E PRÁTICA DE GESTÃO DO ENFERMEIRO EM ESTRATÉGIAS SAÚDE DA FAMÍLIA
}

\author{
Suelen Mateus \\ Enfermeira, Centro Universitário Barriga Verde, \\ suelen.mateus@hotmail.com \\ Silvia Salvador do Prado \\ Enfermeira, Mestra em Educação, Centro Universitário Barriga Verde, \\ sisaprado@yahoo.com \\ Jully Anne Wiggers Duessmann \\ Enfermeira, Centro Universitário Barriga Verde, \\ jullyannew_17@hotmail.com \\ Karla Pickler Cunha \\ Enfermeira, Centro Universitário Barriga Verde, \\ enfermagem@unibave.net \\ Morgana Vandresen \\ Enfermeira, Centro Universitário Barriga Verde, \\ morganavandresen@hotmail.com
}

\section{RESUMO}

Em todo ambiente de saúde, as informações são fundamentais para o desenvolvimento das atividades. Os Sistemas de Informação em Saúde (SIS) são considerados importantes ferramentas para a gestão do trabalho em saúde. Para Benito e Licheski (2009), os sistemas de informação como instrumentos de trabalho em saúde são importantes recursos computacionais de apoio às açôes 
administrativo-burocráticas, sobretudo as que dependem de informaçóes atualizadas. Surge, então, a iniciativa de compreender e vivenciar, in loco, a visão dos enfermeiros inseridos na Estratégia Saúde da Família (ESF), sobre o uso dos SIS como ferramenta de gestão e contribuinte no planejamento e na organização de suas açóes. Esses profissionais têm assumido cada vez mais funçóes de gerenciamento, sendo necessária a utilização de meios que facilitem este processo. $\mathrm{O}$ presente artigo objetiva analisar o gerenciamento dos dados obtidos nos SIS, pelo enfermeiro, na ESF, bem como a sua utilização como ferramenta de gestão no planejamento das açóes em saúde em um território. Também se propóe descrever como o enfermeiro, na sua prática de cuidado, utiliza o SIS para planejar as açóes em saúde, além de identificar os aspectos positivos e negativos considerados pelos enfermeiros, em relação ao uso dos Sistemas de Informação em Saúde. Um dos objetivos básicos dos SIS, na concepção SUS, é possibilitar a análise da situação de saúde no âmbito local, tomando como referencial as microrregióes homogêneas e considerando, necessariamente, as condições de vida da população na determinação do processo saúde-doença (BRASIL, 2005). Dessa forma, os sistemas de informação em saúde congregam um conjunto de dados, informaçóes e conhecimentos utilizados na área de saúde para sustentar o planejamento, o aperfeiçoamento e o processo decisório dos múltiplos profissionais da área da saúde envolvidos no atendimento aos pacientes e aos usuários do sistema de saúde (MARIN, 2010). O SIS é composto por diferentes subsistemas, que produzem dados referentes às atividades em saúde e dados gerais da população de cada área de saúde, gerando bancos de dados, sendo os principais utilizados na atenção básica: Sistema de Informações sobre Mortalidade (SIM); Sistema de Informação sobre Nascidos Vivos (SINASC); Sistema de Informaçóes de Agravos de Notificação (SINAN); Sistema de Informaçóes de Vigilância Alimentar e Nutricional (SISVAN); Sistema de Informação do Câncer (SISCAN); Sistema de Informação do Pré-natal e Nascimento (SISPRENATAL); Sistema de Informação da Atenção Básica (SIAB); Sistema de Informações do Programa Nacional de Imunização (SI-PNI); Programa e-SUS. O presente trabalho é uma pesquisa descritiva exploratória com abordagem qualitativa. Os instrumentos de coleta de dados utilizados foram entrevista semiestruturada e pesquisa documental. A pes- 
quisa foi realizada em Estratégias Saúde da Família de um município de pequeno porte, localizado no sul catarinense, selecionado pelo critério de acessibilidade. Os sujeitos participantes da pesquisa foram cinco enfermeiros das seis Unidades de Saúde da Família existentes no município. As entrevistas foram gravadas, transcritas e interpretadas por meio da análise de conteúdo, proposta por Minayo (2015). A pesquisa documental serviu para verificar a existência ou náo de relatórios de SIS na unidade para análise dos dados. A partir das informaçóes coletadas, apresentamos seus resultados devidamente analisados à luz dos conteúdos baseados na temática proposta por Minayo (2015), sendo definidas duas categorias: Categoria I (avaliação dos sistemas de informação) e Categoria II (utilização e contribuição dos SIS para a prática de gestão). Na Categoria I (avaliação dos sistemas de informação), durante a entrevista, questionamos os enfermeiros sobre a importância dos SIS para o processo de gestão do trabalho e para o cuidar da enfermagem. De forma unânime, todos afirmam a importância dos SIS como ferramenta de planejamento das açóes em saúde, sendo considerado um contribuinte nas tomadas de decisão e instrumentos de armazenamento de dados, capaz de fornecer informaçóes sobre o histórico da população. Em relação aos aspectos positivos considerados pelos enfermeiros ao uso dos SIS, identificamos nas entrevistas que estes são capazes de auxiliar no processo de trabalho, trazendo praticidade na busca por informaçóes. No entanto, ainda existem algumas divergências que impedem o uso de forma efetiva destes sistemas, principalmente no que se diz respeito à conexão com a internet, sendo este considerado o principal ponto negativo em relação ao uso dos SIS. Já na Categoria II (utilização e contribuição dos SIS para a prática de gestão), questionamos os entrevistados em quais situaçóes de cuidado seria necessário utilizar os SIS, as enfermeiras responderam ser durante as atividades de preenchimento da requisição de mamografia, realização de exame preventivo do colo do útero, consulta de pré-natal e controle de vacinas em atraso. Outra questão apontada durante a entrevista foi como a utilização do SIS contribui para o desenvolvimento do cuidado de enfermagem. De maneira geral, observamos que os SIS contribuem para realizar busca ativa na identificação de famílias ou de pessoas vulneráveis, bem como no controle de pacientes atendidos na ESF. Ao compreender que os dados gerados pelos SIS podem servir para criação ou organização 
de açôes em saúde, questionamos os entrevistados de que maneira eles utilizam os dados obtidos pelos SIS e se estes dados são utilizados para a criação de alguma ação em saúde. De maneira geral e unânime, nenhuma resposta foi positiva: os dados são apenas coletados pelos agentes comunitários de saúde. Ressalta-se que, quanto aos aspectos positivos, a maioria dos entrevistados demonstrou afirmaçóes satisfatórias sobre a importância do uso dos SIS. No entanto, ao serem questionados sobre a utilização dos dados para a prática de gestão e para o planejamento de suas açóes em saúde na ESF, os mesmos demonstraram não aplicá-las em seu cotidiano de trabalho, não atendendo, assim, aos requisitos propostos pelo Ministério da Saúde, dentro da Política Nacional de Informação e Informática em Saúde (BRASIL, 2015), restringindo-se apenas ao preenchimento das fichas e consolidação dos dados para a entrega mensal da produçáo na Secretaria Municipal de Saúde. Conforme Barbosa e Forster (2010), para que haja essa possibilidade de detecção e intervenção e, consequentemente, aumento da resolutividade dos problemas de saúde, é necessário que os profissionais saibam seu papel, as habilidades e as competências de que necessitam, além de traçarem estratégias que viabilizem essas açóes. Identificamos, por meio do estudo, a importância que os Sistemas de Informação em Saúde têm como instrumento de apoio na prática de gestão. No entanto, foi possível identificar que ainda existem algumas dificuldades quanto ao acesso a esses sistemas e, principalmente, a sua inutilização no planejamento das açóes em saúde, sendo indispensável que o enfermeiro desempenhe suas atividades junto com comunidade, mas que também tenha o conhecimento, habilidades e, essencialmente, atitudes como gestor de sua ESF, a fim de criar açóes que viabilizem a melhora das condiçôes de saúde-doença da população.

Palavras-chave: Sistemas de Informação em Saúde; Estratégia Saúde da Família; Enfermeiros; Gestão em Saúde.

\section{REFERÊNCIAS}

BARBOSA, D. C. M.; FORSTER, A. C. Sistemas de Informação em Saúde: a perspectiva e a avaliação dos profissionais envolvidos na Atenção Primária à 
Saúde de Ribeirão Preto. Cadernos Saúde Coletiva, São Paulo, v.18, n.3, p.424433, 2010.

BENITO, G. A. V.; LICHESKI, A. P. Sistemas de Informação apoiando a gestão do trabalho em saúde. Revista Brasileira de Enfermagem, Brasília, v.62, n.3, p.447-450, 2009.

BRASIL. Secretaria de Vigilância em Saúde. Guia de vigilância epidemiológica. 6. ed. Brasília: Ministério da Saúde, 2005.

. Ministério da Saúde. Portaria no 589, de 20 de maio de 2015, Institui a Política Nacional de Informaçáo e Informática em Saúde. Brasília: Diário Oficial da Uniāo, 2015.

MARIN, H. F. Sistemas de informação em saúde: considerações gerais. Journal of Health Informatics, São Paulo, v.2, n.1, p.20-24, 2010.

MINAYO, M. C. S. Pesquisa social. 34. ed. Petrópolis: Vozes, 2015. 